\title{
Inflammatory Fibroid Polyps of the Duodenum: A Review of the Literature
}

\author{
A. Peter Wysocki ${ }^{a}$ Graeme Taylor $^{b}$ John A. Windsor ${ }^{a}$ \\ a Hepatobiliary, Pancreatic and Upper Gastro-Intestinal Unit, Department of General Surgery, and \\ ${ }^{b}$ Department of Pathology, Auckland City Hospital, Auckland, New Zealand
}

\section{Key Words}

Inflammatory fibroid polyps - Duodenum, inflammatory

fibroid polyps - Bile duct obstruction - Helicobacter pylori •

Pseudotumour $\cdot$ Eosinophilic granuloma

\begin{abstract}
Background/Aim: An inflammatory fibroid polyp (IFP) is a rare benign submucosal gastro-intestinal lesion with an uncertain origin and natural history. An IFP was first described in the stomach and is rare in the duodenum. Presenting signs and symptoms vary according to anatomical site. This systematic literature review was prompted by the recent presentation of a patient with biliary obstruction caused by a duodenal IFP. Methods: A review of all duodenal IFPs identified in the PubMed database from 1971 onwards is presented within the context of what is known about the lesion at other gastro-intestinal sites. Results: Of approximately 1,000 IFP cases identified, $70 \%$ were of gastric origin, and fewer than $1 \%$ occurred in the duodenum. Duodenal IFPs typically present with non-specific features, and no pre-operative diagnoses of lesions at this site have been made. Microscopy reveals spindle-shaped cells, prominent capillaries, and an inflammatory cell filtrate. Immunohistochemistry shows the lesions to be CD34 and vimentin positive, but CD117, S100, and factor VIII negative. Local recurrence is most unusual following complete resection. Conclusions: This rare benign entity in the duodenum should be included in the differential diagnosis of all peripancreatic masses. The advent of
\end{abstract}

endoscopic ultrasound may allow pre-operative diagnosis of the lesion in the duodenum, enabling local resection and potentially avoiding unnecessary pancreatoduodenectomy.

\section{Introduction}

An inflammatory fibroid polyp (IFP) is a rare benign lesion of the gastro-intestinal (GI) tract. It is a solitary, non-encapsulated, usually submucosal, polypoid lesion characterized by oedematous connective tissue and numerous small blood vessels with an eosinophilic inflammatory infiltrate. First described by Vanek [1] in 1949, the term IFP was coined later in 1953 by Helwig and Ranier [2]. IFP has also been referred to as gastric eosinophilic submucosal granuloma [1], Vanek's tumour [3], eosinophilic granuloma [4], haemangiopericytoma [4, 5], myxoma [6], inflammatory pseudotumour [4], fibroma with eosinophilic infiltration [4], and polypoid myoendothelioma [7] which has led to confusion in the literature.

The natural history of IFP is unknown, but rapid growth may occur within a few months [8], and sizes of up to 20 $\mathrm{cm}$ have been reported [9]. The pre-operative diagnosis is rarely suspected or made $[4,10,11]$. The lesion is usually found in the stomach [5], but can occur throughout the GI tract [12]. An IFP in the duodenum is very unusual [5, 


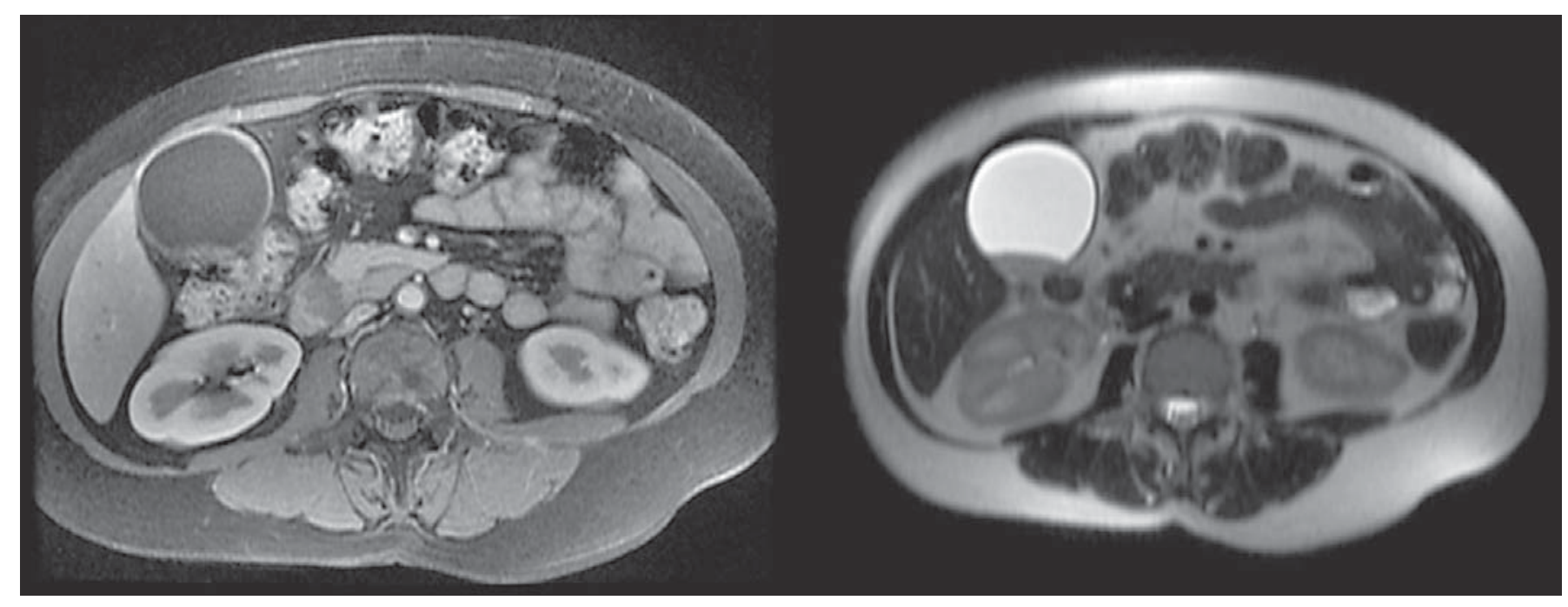

Fig. 1. Magnetic resonance imaging. In the upper slices the common bile duct is dilated (not shown). The gallbladder contains stones. On $\mathrm{T}_{2}$ imaging (right), there is a hypodense mass which indents the duodenal lumen. The 26-mm mass is of intermediate signal density on $\mathrm{T}_{1}$ imaging (left) and is predominantly at the interface between pancreatic head and duodenum. Medially the lesion is lobulated.

13-15], and to date there has been only one published attempt at a clinicopathological evaluation of IFP at this site [14]. This literature review of duodenal IFP is presented within the context of what is known about the lesion at other GI sites and was prompted by the recent presentation at Auckland City Hospital of a patient with biliary obstruction caused by an IFP in the duodenum. The patient was a 53-year-old woman who presented with a short history of right upper quadrant pain radiating to the back. Clinical examination was unremarkable. Her bilirubin and amylase levels were normal, but her other liver function test results were elevated: $\gamma$-glutamyltransferase 656 (normal 0-50) U/l, alkaline phosphatase 156 (normal 40-120) U/l, aspartate transaminase 418 (normal <40) U/l, and alanine transaminase 346 (normal <45) U/l.

At endoscopic retrograde cholangiopancreatography, the major duodenal papilla was firm and ulcerated. The cholangiogram showed a short distal bile duct stricture and a dilated bile duct. Multiple biopsies were not diagnostic. Magnetic resonance imaging revealed a $26-\mathrm{mm}$ mass in the pancreatic head, causing dilation of the biliary tree and indentation (but not obstruction) of the duodenum (fig. 1). The mass was situated adjacent to the ampulla of Vater, more within the duodenal wall than in the pancreas (fig. 2). A classical pancreatoduodenectomy was performed, and the patient was discharged well from hospital 27 days following surgery on a normal diet and drain free. Postoperatively, the patient's Helicobacter pylori IgG antibody titre was found to be elevated, and eradication therapy was prescribed.

Postoperative examination of the specimen showed a firm $24 \times 16 \times 25$-mm mass in the second part of the duodenum, with an overlying $10 \times 8-\mathrm{mm}$ area of mucosal ulceration. Histology revealed a mixture of bland spindle and stellate cells, along with inflammatory cells set within a collagenous background (fig. 3). The inflammatory cells were predominantly eosinophils, with smaller amounts of lymphocytes and plasma cells. Mesenchymal cells did not show pleomorphism, and mitoses were difficult to detect. The spindle cells were positive for CD34 on immunostaining, although staining for CD34 was stronger in tumour vessels. The tumour was negative for S100, smooth muscle actin, CD117, and bcl-2. There was no evidence of malignancy. Although the lesion was not polypoid, its profile was otherwise consistent with IFP.

A search of the PubMed database [http://www.ncbi. nlm.nih.gov/PubMed] from 1971 onwards using the search terms 'inflammatory', 'fibroid', and 'polyp' yielded 46 relevant publications. Searches using the alternative terms 'submucosal granuloma', 'fibroma with eosinophilic infiltration', 'duodenal haemangiopericytoma', and 'Vanek's tumour' yielded a further three papers. References for the larger published series were then searched to identify all duodenal IFP case reports. Non-English publications were excluded from the analysis, with the exception of one recent paper deemed to be significant [16]. 


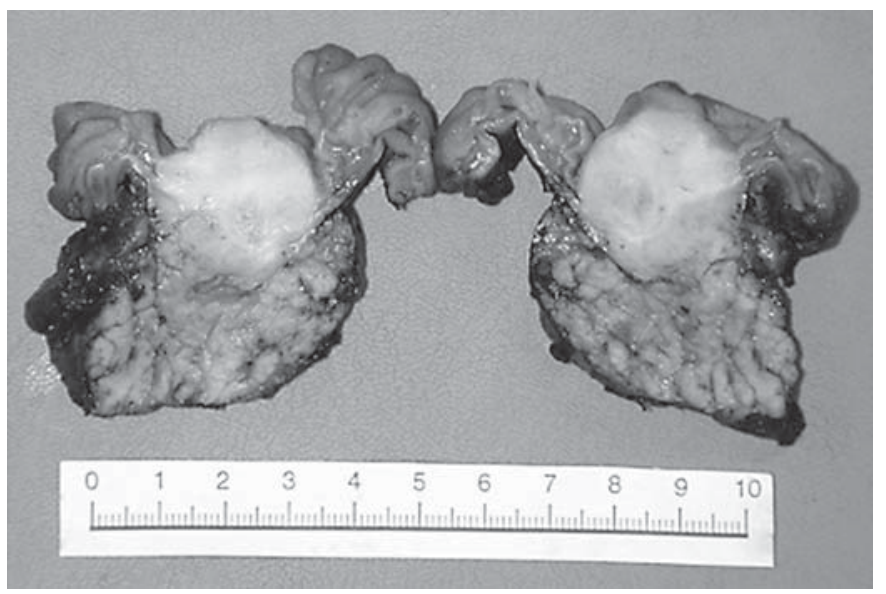

Fig. 2. Formalin-fixed gross specimen. The lower portion represents the pancreatic head with overlying duodenal mucosa. The tumour is the pale/white submucosal lesion.

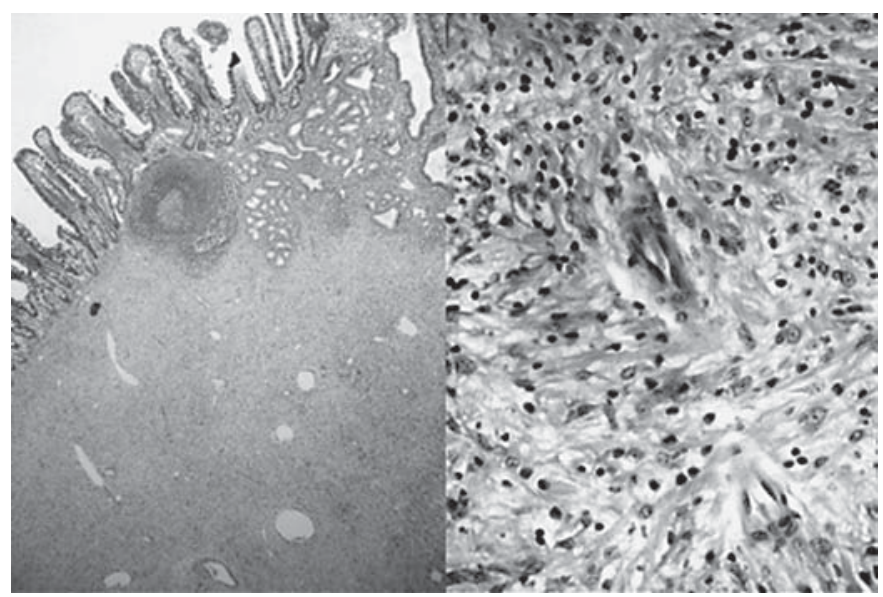

Fig. 3. Histology of an IFP lesion at low (left) and high (right) magnification. The left image shows duodenal mucosa, major duodenal papilla, and the underlying lesion. The right image shows typical high-power features, including numerous intralesional eosinophils.
Table 1. Presenting signs and symptoms of IFPs according to anatomical site

\begin{tabular}{lccccc}
\hline $\begin{array}{l}\text { Location/ } \\
\text { clinical features }\end{array}$ & $\begin{array}{l}\text { Frequency } \\
\%\end{array}$ & Pain & Bleeding & Obstruction & Incidental \\
\hline Stomach & 70 & + & ++ & & ++ \\
Small bowel & 23 & ++ & & ++ & + \\
Colon and rectum & 4 & & + & + \\
Gallbladder & 1 & + & ++ & \\
Oesophagus & 1 & ++ & + & \\
$\begin{array}{l}\text { Duodenum } \\
\text { Appendix }\end{array}$ & 1 & ++ & & \\
\hline
\end{tabular}

Blank = Not described $;+=$ common; $++=$ usual.

\section{Anatomical Site}

At least 1,000 IFPs have been described thus far in the literature, of which $70 \%$ have been gastric in origin (see table 1 for distribution). Other GI sites affected (in decreasing order of frequency) were small bowel (mainly the ileum), colon, gallbladder, oesophagus, duodenum, appendix, and rectum. In the earliest review of the IFP literature, Johnstone and Morson [5] reported 3 cases of duodenal IFP, 2 of whom were referenced from the earlier German literature. A detailed description of an unusually long polyp in the third part of the duodenum was published in 1980 [14]. Two duodenal IFPs were reported by Shimer and Helwig [13], but limited clinicopathological data are provided. A recent report of a duodenal IFP has been published in abstract form [15], with limited clinical information. A summary of these case reports is provided in table 2. Four duodenal haemangiopericytomas reviewed by Binder et al. [17] were locally invasive tumours with haematogenous spread, so bear no resemblance to IFP and were excluded from the analysis.

\section{Demographic and Clinical Characteristics}

Patients with IFP typically present in the 5th to 7 th decade of life $[14,18,19]$. Occurrence in children is rare [20]. Both sexes appear to be equally affected, although the female-to-male ratios have ranged from 2.8:1 [21] to 0.7:1 [5]. Presenting signs and symptoms vary according 
Table 2. Summary of eight case reports of duodenal IFPs

\begin{tabular}{|c|c|c|c|c|c|c|c|c|}
\hline Authors & $\begin{array}{l}\text { Age } \\
\text { years }\end{array}$ & Sex & Location & $\begin{array}{l}\text { Size } \\
\mathrm{cm}\end{array}$ & Mucosa & Morphology & Eosinophils & Presentation \\
\hline Ott et al. [14] & 56 & male & D3 & 12.5 & eroded & elongated & scant & $\begin{array}{l}\text { epigastric pain and } \\
\text { melaena }\end{array}$ \\
\hline Johnstone and Morson [5] & 50 & female & D1 & 1.25 & & & numerous & $\begin{array}{l}\text { abdominal pain } \\
\text { and 'dyspepsia' }\end{array}$ \\
\hline Johnstone and Morson [5] & & & $\begin{array}{l}\text { duodenum and } \\
\text { jejunum }\end{array}$ & & & & & \\
\hline Johnstone and Morson [5] & & & duodenum & & & & & \\
\hline Soon and Lin [15] & & & duodenum & & & & & blood loss \\
\hline Shimer and Helwig [13] & & & D2 & & & & & \\
\hline Shimer and Helwig [13] & & & $\begin{array}{l}\text { (?) distal } \\
\text { duodenum }\end{array}$ & & & mass & & \\
\hline Current patient & 53 & female & D2 & 2.5 & ulcerated & mass & numerous & $\begin{array}{l}\text { epigastric pain and } \\
\text { elevated liver } \\
\text { function test results }\end{array}$ \\
\hline
\end{tabular}

to anatomical site (table 1). Duodenal IFPs typically present with non-specific features of abdominal pain or upper GI blood loss (table 2). Peripheral blood smears show normal eosinophil and IgE levels in virtually all patients with IFP, regardless of GI location $[5,13,14,22]$. The majority of the lesions reported have been $<2 \mathrm{~cm}$ in diameter [14]. Multiple synchronous and metachronous disease is rare. Two synchronous gastric IFPs have been reported twice $[23,24]$ and four once [23]. Two synchronous IFPs beyond the ligament of Treitz have been reported twice $[13,25]$. There has been 1 case of a synchronous duodenal and jejunal lesion [5].

\section{Pathogenesis}

The aetiology of IFPs is uncertain [22]. Early debate as to whether the lesion is neoplastic or not has now been resolved in favour of it being a benign reactive phenomenon similar to a granuloma $[4,5]$, occurring in response to an unknown irritant $[9,22,26-28]$. However, no foreign body has as yet been found in association with IFP [29]. Although its macroscopic appearance is similar to that of a pyogenic granuloma of the skin, the two conditions share no histological similarities [5, 13]. IFP is unrelated to eosinophilic enteritis, although it has been suggested that IFP may represent a mild or aborted form of this rare disorder [24].

Duodenal Inflammatory Fibroid Polyps
The IFP may be associated with concurrent or synchronous neoplastic and neoplastic GI lesions, but a causal relationship is not supported by the literature [21,23]. There have been isolated reports of IFP at various sites co-existing with granular cell tumour [30] and some immune system disorders, including human immunodeficiency virus infection [31], ankylosing spondylitis [32], Crohn's disease [13,33], and neurofibromatosis [34], but these are not consistent findings and likely to be coincidental [13]. The possibility that IFP is caused by a parasite has been raised, but there is scant literature to support this theory $[21,29]$. Some have suggested that localized vascular inflammation may occur in response to an as yet unidentified factor $[27,28]$ that induces hyperplasia of stromal cells and vessels [32].

After the first report of a patient with $H$. pylori gastritis and a gastric IFP in 1996 [35], it was postulated that some gastric IFPs are the result of the immune response to chronic $H$. pylori infection [36]. There has also been a Japanese report of a gastric IFP diagnosed on the basis of the endoscopic appearance which regressed endoscopically within 3 months after $H$. pylori eradication [11]. However, since this paper was published, it has been pointed out that the endoscopic ultrasound (EUS) findings in that patient were not typical of IFP [37], and the absence of histological confirmation does not allow for any therapeutic inferences to be drawn. The aetiological role and mechanism of $H$. pylori in IFP, if any, remain speculative [11].

Dig Surg 2007;24:162-168 


\section{Diagnosis}

There is a single report of a correct pre-operative diagnosis of a gastric IFP using a combination of oesophagogastroduodenoscopy, EUS, and computed tomography scan [10], but not in the duodenum. The relevant radiological literature is limited, pertaining mainly to gastric and small-bowel IFPs, and fails to identify specific diagnostic criteria to differentiate IFPs from other more commonly detected lesions $[4,38]$.

\section{Endoscopy}

Oesophagogastric and duodenal IFPs are seen on upper GI endoscopy as protruding intramural lesions with a smooth and often ulcerated mucosa. Colorectal lesions are identified at colonoscopy and small-bowel lesions at the time of surgery, usually for obstruction. Macroscopically, the differential diagnosis includes GI stromal tumour (GIST) and submucosal lipoma [39]. Endoscopic biopsies are unhelpful for the diagnosis of IFPs $[18,39$, 40 ], with only $10 \%$ of the gastric lesions diagnosed correctly prior to resection [18].

EUS has emerged as a promising diagnostic tool for gastric IFPs $[39,41]$. On EUS, these lesions show indistinct margins, are hypo-echogenic and homogeneous, and are located within the second and third sonographic layers of the gastric wall. Internal echoes may be seen which correspond to the numerous blood vessels within the lesion [41]. In contrast, a GIST is transmural [42] and, like a lipoma, has well-defined margins on EUS [39]. Thus far, there have been no reports of a duodenal IFP being diagnosed pre-operatively by EUS.

\section{Histopathology}

Histologically, an IFP appears as an exuberant [13], non-encapsulated, localized proliferation of mononuclear spindle-shaped cells [7] with an inflammatory infiltrate often dominated by eosinophils [23]. The non-encapsulated proliferating spindle cells correspond with the indistinct margins seen on EUS [41]. IFPs are typically vascular, with a network of variably sized blood vessels throughout [43]. The arrangement of spindle-shaped cells is occasionally concentric, with an 'onion-skin'-like appearance [7, 24]. Focal areas of surface ulceration are sometimes seen [6]. The lesion is thought to arise in the lower layer of the lamina propria [23] and, although typically polypoidal [5], may be sessile [5, 21]. Unlike GISTs which push aside bundles of the muscularis propria, IFPs cause splitting, fraying, and atrophy of the muscle wall layers [6].
Four distinct histological patterns have been described for gastric IFPs, i.e., classical fibrovascular, nodular, sclerotic, and oedematous [21]. There has been a report of nuclear pleomorphism, but this is considered to be very unusual $[5,7,27,43]$. There is some evidence that the histological pattern of gastric and small-bowel IFPs may be determined by the age of the lesion $[21,23]$. Kim and Kim [21] noted that smaller lesions have a more marked concentric distribution of spindle-shaped cells and that, as the lesion becomes bigger, the dominant histological type progresses through the different phases already mentioned. Different histological patterns may co-exist in the same lesion, and it has been suggested [21] that the oedematous pattern is an artefact of intestinal obstruction.

Electron microscopy has further characterized four components of gastric and intestinal IFPs: (1) uniform mesenchymal fibroblast-like, stellate, or spindle-shaped cells with abundant rough endoplasmic reticulum; (2) inflammatory cells (eosinophils, plasma cells, lymphocytes) in capillary lumen and interstitium; (3) prominent arborizing vascular channels as well as closed capillaries, and (4) loose granulofibrillar material comprising the extracellular space [19]. It should be noted that eosinophilic infiltration whilst characteristic of IFP is not pathognomonic and is found in other unrelated disorders [38]. For example, fibroblasts in asthmatics are known to secrete eotaxin, a potent eosinophil chemotactic factor [44], but whether this mechanism accounts for the eosinophilic infiltrate in IFP needs further investigation.

After GIST and sarcoma [45] have been excluded histologically, the differential diagnosis of IFP includes haemangioendothelioma, haemangiopericytoma [3], spindle cell carcinoid [9], T cell lymphoma [9], solitary fibrous tumour [46], and inflammatory pseudotumour $[26,46]$ and should exclude an identifiable polyposis syndrome. The latter occurs in children and generally with systemic manifestations [9]. Moreover, an inflammatory pseudotumour is usually larger than an IFP, with diffuse margins and few eosinophils [9].

An ultrastructural study [7] has failed to determine the histogenesis of IFPs. The main cellular component of IFPs remains unclear, but is of mesenchymal origin [23].

\section{Immunohistochemistry}

Immunohistochemical staining of the spindle cell component of IFPs from various GI sites shows almost $100 \%$ positivity for vimentin [4] and CD34 [27], but variable staining for smooth muscle actin, HHF-35, KP1, and Mac 387 [23]. Neuron-specific enolase and S-100 binding 
are not observed $[7,27,43]$, militating against a neurogenic origin. The spindle-shaped cells lack factor-VIIIassociated antigen $[7,19,26,27,43]$, arguing against a vascular origin. On the basis of the almost complete staining of IFP spindle cells for CD34, it has been suggested that the cell of origin is a primitive perivascular fibroblast [7]. Pantanowitz et al. [22] demonstrated that these lesions stain uniformly for CD35 and overexpress cyclin D1 (suggesting a defect in the cell cycle regulation) and concluded that the proliferating stromal cells are of dendritic cell origin with myofibroblastic differentiation. IFPs have been shown to stain inconsistently for HMB45, PGM1, desmin, h-caldesmon, EMA, ALK-1, SCF, bcl-2, CD21, CD23, HHV8, and EBER [22, 27].

Genotype profiling of twelve predominantly gastric IFPs showed no loss of heterozygosity at any of the 14 commonly analyzed tumour suppressor gene loci [26], lending further support to the view that these lesions are not neoplastic. An immunohistochemical study [27] does not support the suggestion that IFP is a subtype of GIST, as staining for CD117 was not detected [22, 26].

\section{Treatment}

In order to relieve symptoms and resolve diagnostic uncertainty, complete resection is the treatment of choice for IFP. Endoscopic polypectomy is the ideal technique, if the lesion is polypoidal and accessible, as is usually the case in stomach and colon. Given that IFPs arise from the submucosa and may be sessile, endoscopic resection may result in perforation or incomplete resection and increases the risk of local recurrence. There has been a report of local recurrence at the cardio-oesophageal junction fol- lowing endoscopic submucosal excision [40], but the nature of the initial microscopic resection margin is unclear in this paper, and the possibility that the observation may reflect residual disease rather than true recurrence cannot be excluded.

Clustering of multiple small-bowel IFPs has been documented in two families [16, 47] and is called the 'Devon polyposis syndrome'. There were no local recurrences following 15 operations, but all the women in both series developed multiple IFPs at other sites within the small bowel $[14,16,48]$. No patient with this syndrome has been treated for a duodenal IFP.

\section{Conclusions}

This is the first systematic clinicopathological correlation of IFP in the duodenum. The histological and immunohistochemical findings in our patient support the diagnosis of a nodular duodenal IFP. Although there have been previous reports of a duodenal suture granuloma causing bile duct [49] and pancreatic duct [50] obstruction, this is also the first time to our knowledge that a duodenal IFP causing common biliary compression in a H.-pylori-positive patient has been described. Surgeons should be aware of the existence of this benign entity in the duodenum which may mimic malignant spindle cell tumours such as GIST, leiomyoma, leiomyosarcoma, and schwannoma on superficial biopsies. Duodenal IFP should thus be included in the differential diagnoses of all peripancreatic masses. EUS should improve our ability to make a pre-operative diagnosis of IFP in the duodenum, enabling local resection and, in some patients, may avoid unnecessary pancreatoduodenectomy.

\section{References}

1 Vanek J: Gastric submucosal granuloma with eosinophilic infiltration. Am J Pathol 1949;25:397-411.

$>$ Helwig EB, Ranier A: Inflammatory fibroid polyps of the stomach. Surg Gynecol Obstet 1953;96:335-367.

\3 Daum O, Hes O, Vanecek T, Benes Z, Sima R, Zamecnik M, Mukensnabl P, Hadravska S, Curik R, Michal M: Vanek's tumor (inflammatory fibroid polyp). Report of 18 cases and comparison with three cases of original Vanek's series. Ann Diagn Pathol 2003;7: 337-347.
-4 Kuestermann SA, Saleeb SF, Teplick SK: General case of the day. Jejunal intussusception caused by an inflammatory fibroid polyp (IFP). Radiographics 1999;19:539-541.

5 Johnstone JM, Morson BC: Inflammatory fibroid polyp of the gastrointestinal tract. Histopathology 1978;2:349-361.

6 Benjamin SP, Hawk WA, Turnbull RB: Fibrous inflammatory polyps of the ileum and cecum: review of five cases with emphasis on differentiation from mesenchymal neoplasm. Cancer 1977;39:1300-1305.

7 Trillo AA, Rowden G: The histogenesis of inflammatory fibroid polyps of the gastrointestinal tract. Histopathology 1991;19:431436.
8 Godey SK, Diggory RT: Inflammatory fibroid polyp of the oesophagus. World J Surg Oncol 2005;3:30.

-9 Savargaonkar P, Morgenstern N, Bhuiya T: Inflammatory fibroid polyp of the ileum causing intussusception: report of two cases with emphasis on cytologic diagnosis. Diagn Cytopathol 2003;28:217-221.

10 Fuke H, Hashimoto A, Shimizu A, Yoshimura H, Nakano T, Shiraki K: Computed tomographic image of an inflammatory fibroid polyp of the stomach. Clin Imaging 2003;27: 400-402. 
-11 Matsuhashi N, Nakajima A, Nomura S, Kaminishi M: Inflammatory fibroid polyps of the stomach and Helicobacter pylori. J Gastroenterol Hepatol 2004;19:346-347.

-12 Solito B, Anselmino M, Tognetti A, Vignati S, Rossi M: Rare case of inflammatory fibrous polyp of the esophagus. Dis Esophagus 2002;15:326-329.

-13 Shimer GR, Helwig EB: Inflammatory fibroid polyps of the intestine. Am J Clin Pathol 1984;81:708-714.

- 14 Ott DJ, Wu WC, Shiflett DW, Pennell TC: Inflammatory fibroid polyp of the duodenum. Am J Gastroenterol 1980;73:62-64.

-15 Soon MS, Lin OS: Inflammatory fibroid polyp of the duodenum. Surg Endosc 2000;14: 86.

16 Bayle S, Rossi P, Bagnères D, Demoux AL, Ashero A, Dales JP, Vitton V, Frances Y, Granel B: Ileum inflammatory fibroid polyp revealed by intussusception: about one familial case (in French). Rev Med Interne 2005;26:233-237.

-17 Binder SC, Wolfe HJ, Deterling RA Jr: Intraabdominal hemangiopericytoma. Report of four cases and review of the literature. Arch Surg 1973;107:536-543.

-18 Stolte M, Finkenzeller G: Inflammatory fibroid polyp of the stomach. Endoscopy 1990; 22:203-207.

-19 Navas-Palacios JJ, Colina-Ruizdelgado F, Sanchez-Larrea MD, Cortes-Cansino J: Inflammatory fibroid polyps of the gastrointestinal tract. An immunohistochemical and electron microscopic study. Cancer 1983;51: 1682-1690.

-20 Chongsrisawat V, Yimyeam P, Wisedopas N, Viravaidya D, Poovorawan Y: Unusual manifestations of gastric inflammatory fibroid polyp in a child. World J Gastroenterol 2004; 10:460-462.

-21 Kim YI, Kim WH: Inflammatory fibroid polyps of gastrointestinal tract. Evolution of histologic patterns. Am J Clin Pathol 1988; 89:721-727.

-22 Pantanowitz L, Antonioli DA, Pinkus GS, Shasafaei A, Odze RD: Inflammatory fibroid polyps of the gastrointestinal tract: evidence for a dendritic cell origin. Am J Surg Pathol 2004;28:107-114.

-23 Kolodziejczyk P, Yao T, Tsuneyoshi M: Inflammatory fibroid polyp of the stomach. A special reference to an immunohistochemical profile of 42 cases. Am J Surg Pathol 1993; 17:1159-1168.
24 Suen KC, Burton JD: The spectrum of eosinophilic infiltration of the gastrointestinal tract and its relationship to other disorders of angiitis and granulomatosis. Hum Pathol 1979;10:31-43.

25 Jabar MF, Prasannan S, Gul YA: Adult intussusception secondary to inflammatory polyps. Asian J Surg 2005;28:58-61.

26 Ozolek JA, Sasatomi E, Swalsky PA, Rao U, Krasinskas A, Finkelstein SD: Inflammatory fibroid polyps of the gastrointestinal tract: clinical, pathologic, and molecular characteristics. Appl Immunohistochem Mol Morphol 2004; 12:59-66.

27 Wille P, Borchard F: Fibroid polyps of intestinal tract are inflammatory-reactive proliferations of CD34-positive perivascular cells. Histopathology 1998;32:498-502.

28 Fogt F, Zimmerman RL, Buyske J: Inflammatory fibroid polyp of the gallbladder. Histopathology 1998;33:583-584.

29 Stolte M, Sticht T, Eidt S, Ebert D, Finkenzeller G: Frequency, location, and age and sex distribution of various types of gastric polyp. Endoscopy 1994;26:659-665.

30 Bickel A, Szvalb S, Eitan A, Cohen I: The coexistence of inflammatory fibroid polyp and granular cell tumor in the same gastric lesion. Am J Gastroenterol 1994;89:20902091.

31 Simmons MZ, Cho KC, Houghton JM, Levine CD, Javors BR: Inflammatory fibroid polyp of the esophagus in an HIV-infected individual: case study. Dysphagia 1995;10: 59-61.

32 Muniz-Grijalvo O, Reina-Campos F, Borderas F: Could a fibroid polyp be a manifestation of enteropathy induced by nonsteroidal anti-inflammatory drugs? Am J Gastroenterol 1997;92:170-171.

33 Williams GR, Jaffe S, Scott CA: Inflammatory fibroid polyp of the terminal ileum presenting in a patient with active Crohn's disease. Histopathology 1992;20:545-547.

34 Ng C, Lam KY, Gupta TS, Ho YH: Inflammatory fibroid polyp of the caecum in a patient with neurofibromatosis. Ann Acad Med Singapore 2004;33:797-799.

35 Buciuto R, Kullman E, Boeryd B, Borch K: Helicobacter pylori gastritis associated with a gastric inflammatory fibroid tumour and sarcoidosis. Eur J Surg 1996;162:421-424.

36 Shalom A, Wasserman I, Segal M, Orda R: Inflammatory fibroid polyp and Helicobacter pylori. Aetiology or coincidence? Eur J Surg 2000;166:54-57.

>37 Matsushita M, Okazaki K: Atypical EUS features of gastric inflammatory fibroid polyps. Gastrointest Endosc 2005;61:637-638; author reply 638 .
38 Harned RK, Buck JL, Shekitka KM: Inflammatory fibroid polyps of the gastrointestinal tract: radiologic evaluation. Radiology 1992; 182:863-866.

-39 Sadamoto Y, Kubo H, Tanaka M, Szumilo J, Cwik G, Wallner G: Gastrointestinal-gastric inflammatory fibroid polyp. J Gastroenterol Hepatol 2001;16:1069.

40 Zinkiewicz K, Zgodzinski W, Dabrowski A, Szumilo J, Cwik G, Wallner G: Recurrent inflammatory fibroid polyp of cardia: a case report. World J Gastroenterol 2004;10:767768.

41 Matsushita M, Hajiro K, Okazaki K, Takakuwa H: Gastric inflammatory fibroid polyps: endoscopic ultrasonographic analysis in comparison with the histology. Gastrointest Endosc 1997;46:53-57.

42 Chan JK: Images in pathology. GIST versus inflammatory fibroid polyp. Int J Surg Pathol 2001;9:147.

43 Mori M, Tamura S, Enjoji M, Sugimachi K: Concomitant presence of inflammatory fibroid polyp and carcinoma or adenoma in the stomach. Arch Pathol Lab Med 1988;112: 829-832.

44 Minshall EM, Hamid QA: Fibroblasts: a cell type central to eosinophil recruitment? Clin Exp Allergy 2000;30:301-303.

45 Shigeno T, Fujimori K, Nakatsuji Y, Kaneko Y, Maejima T: Gastric inflammatory fibroid polyp manifesting massive bleeding and marked morphological changes for a short period. J Gastroenterol 2003;38:611-612.

46 Eslami-Varzaneh F, Washington K, Robert ME, Kashgarian M, Goldblum JR, Jain D: Benign fibroblastic polyps of the colon: a histologic, immunohistochemical, and ultrastructural study. Am J Surg Pathol 2004;28: 374-378.

47 Anthony PP, Morris DS, Vowles KD: Multiple and recurrent inflammatory fibroid polyps in three generations of a Devon family: a new syndrome. Gut 1984;25:854-862.

48 Allibone RO, Nanson JK, Anthony PP: Multiple and recurrent inflammatory fibroid polyps in a Devon family ('Devon polyposis syndrome'): an update. Gut 1992;33:10041005

49 Murphy JR, Shay SS, Moses FM, Braxton J, Jaques DP, Wong RK: Suture granuloma masquerading as malignancy of the biliary tract. Dig Dis Sci 1990;35:1176-1179.

50 Sawin R, Brooks DC: Chronic pancreatitis secondary to an inflammatory polyp of the duodenum 25 years after Billroth II reconstruction. Surgery 1988;104:575-576. 